\title{
FORMAÇÃO EXECUTIVA EM BIM: A FGV NA CAPACITAÇÃO DE GESTORES
}

\author{
Modalidade: Planejamento de inserção de BIM na educação
}

\section{PROCESSO}

A adoção BIM pelas empresas de arquitetura e engenharia, após a sanção do decreto $n^{\circ}$ 10.306 de 02 de abril de 2020, com as demandas governamentais, passou a ser necessária para a Indústria da

Construção. Nesse contexto, a Fundação Getulio Vargas (FGV), se estruturou para entregar para o mercado o curso de Formação Executiva em BIM, cujo principal objetivo é desenvolver nos gestores as competências necessárias para liderar equipes, empresas e projetos no ambiente BIM, de modo a apoiar e impulsionar a adoção a partir das demandas geradas. $A$ formação de um gestor deve acontecer de forma rápida e abordar diversos instrumentos estratégicos para 0

Figura 1: Estratégias desenvolvidas nas disciplinas

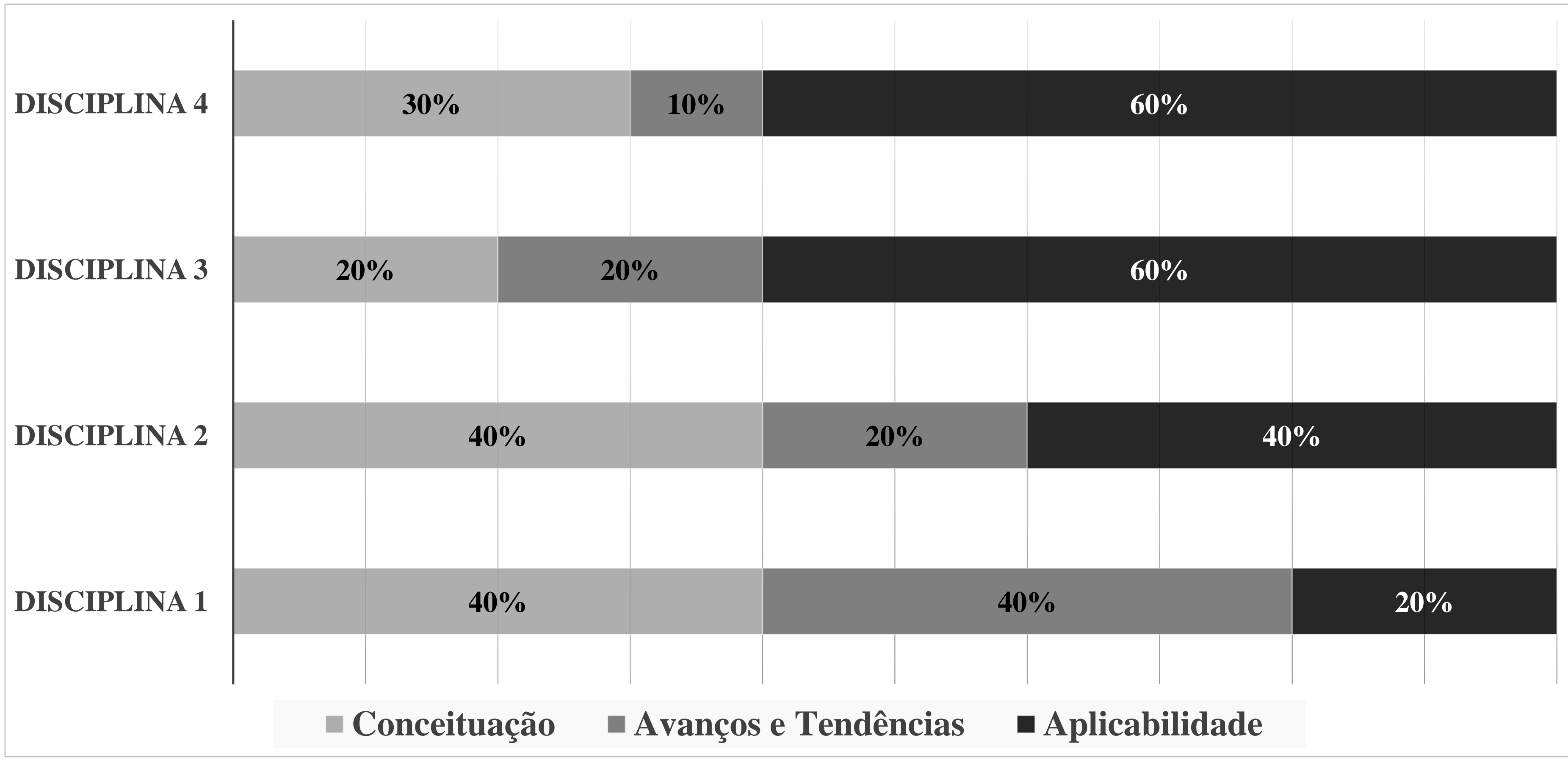

\section{TECNOLOGIAS}

\section{POLÍTICAS}

0 programa de Formação Executiva em BIM é ministrado de forma síncrona e mediada por tecnologia. A ferramenta principal utilizada é a plataforma Zoom e para colaboração e networking entre os alunos, também são utilizados outros aplicativos como Eclass FGV, Slido e Jamboard.

Em relação as tecnologias BIM, como estas são abordadas com foco no planejamento estratégico dos negócios realizados pelas organizações, nenhum software é utilizado pelos alunos ao longo do desenvolvimento do conteúdo ministrados. desenvolvimento e sustentabilidade dos negócios, sendo ele público ou privado.

Segundo Succar (2019), os níveis de competências a serem desenvolvidos em uma empresa são: Gerencial, Administrativo, Funcional, Operacional, Técnico, de Implementação, de Suporte e Pesquisa e Desenvolvimento. Assim, para a formatação da capacitação, chegou se a um Programa de Formação que foi enquadrado na categoria dos cursos de pós-graduação de Curta e Média Duração e estruturado com quatro disciplinas com dezesseis horas cada, totalizando sessenta e quatro horas, cujas estratégias estão detalhadas na figura 1.

\author{
1- PROARQ-UFRJ/D5/FGV, \\ contato@duduribeiro.com.br \\ 2- FGV, pedro.seixas@fgv.br \\ 3 - PROARQ-UFRJ/FGV /Firjan SENAI, \\ crisarqrj@gmail.com \\ 4. - PROARQ-UFRJ/FGV,
}

cricanuto@gmail.com

\section{INTRODUÇÃO}

0 Programa de Formação Executiva em BIM da Fundação Getulio Vargas (FGV) surgiu da necessidade de capacitar gestores, empresários e profissionais que atuam no nível estratégico das organizações ligadas direta ou indiretamente à indústria da construção civil.

Ao se tratar do nível gerencial, assuntos como Gerenciamento Geral a partir da adoção de novos sistemas e fluxos de trabalho, Liderança, Planejamento estratégico, Gestão Organizacional e Desenvolvimento de negócios e gestão de clientes se apresentam como itens de foco.

A Formação Executiva em BIM, no portfólio da FGV se configura como um importante instrumento no processo de transformação digital da indústria da construção civil, contribuindo tanto para 0 impulsionamento da adoção BIM a partir da capacitação dos gestores como no atendimento das demandas de contratação do governo federal, que desde janeiro de 2021, exigem seu uso em projetos e obras.

\section{AGRADECIMENTOS}

Agradecemos a Fundação Getulio Vargas e a CAPES no apoio a este trabalho. 